$$
\text { CONF-9706104--1 }
$$

To be published in Effects of Radiation on Materials, 18th International Symposium, ASTM STP 1325, R. K. Nanstad, M. L. Hamilton, F. A. Garner, and A. S. Kumar, Eds., American Society for Testing and Materials, 1997.

\title{
COMPARISON OF DIFFERENT EXPERIMENTAL AND ANALYTICAL MEASURES OF THE THERMAL ANNEALING RESPONSE OF NEUTRON-IRRADIATED RPV STEELS ${ }^{*}$
}

\author{
S. K. Iskander, M. A. Sokolov, and R. K. Nanstad
}

Metals and Ceramics Division

OAK RIDGE NATIONAL LABORATORY

P.O. Box 2008

Oak Ridge, TN 37831-6151

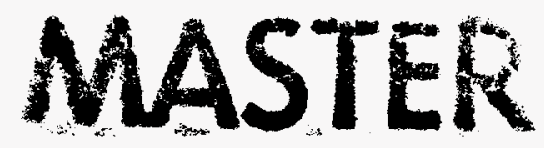

\footnotetext{
The submitted manuscript has been authored by

a contractor of the U.S. Government under contract No. DE-AC05-96OR22464. Accordingly, the U.S. Government retains a nonexclusive, royalty-free license to publish or reproduce the published form of this contribution, or allow others to do so, for U.S. Government purposes.
}

${ }^{*}$ Research sponsored by the Office of Nuclear Regulatory Research, U.S. Nuclear Regulatory Commission, under Interagency Agreement DOE 1886-8109-8L with the U.S. Department of Energy under Contract DE-AC05-960R22464 with Lockheed Martin Energy Research Corp. 


\section{DISCLAIMER}

This report was prepared as an account of work sponsored by an agency of the United States Government. Neither the United States Government nor any agency thereof, nor any of their employees, make any warranty, express or implied, or assumes any legal liability or responsibility for the accuracy, completeness, or usefulness of any information, apparatus, product, or process disclosed, or represents that its use would not infringe privately owned rights. Reference herein to any specific commercial product, process, or service by trade name, trademark, manufacturer, or otherwise does not necessarily constitute or imply its endorsement, recommendation, or favoring by the United States Government or any agency thereof. The views and opinions of authors expressed herein do not necessarily state or reflect those of the United States Government or any agency thereof. 


\section{DISCLAIMER}

Portions of this document may be illegible in electronic image products. Images are produced from the best available original document. 
S. K. Iskander, ${ }^{1}$ M. A. Sokolov, ${ }^{1}$ and R. K. Nanstad ${ }^{1}$

\title{
COMPARISON OF DIFFERENT EXPERIMENTAL AND ANALYTICAL MEASURES OF THE THERMAL ANNEALING RESPONSE OF NEUTRON-IRRADIATED RPV STEELS
}

REFERENCE: Iskander, S. K., Sokolov, M. A., and Nanstad, R. K., "Comparison of Different Experimental and Analytical Measures of the Thermal Annealing Response of Neutron-Irradiated RPV Steels," Effects of Radiation on Materials: 18th International Symposium, ASTM STP 1325, R. K. Nanstad, M. L. Hamilton, F. A. Garner, and A. S. Kumar, Eds., American Society for Testing and Materials, 1997.

\begin{abstract}
The thermal annealing response of several materials as indicated by Charpy transition temperature (TT) and upper-shelf energy (USE), crack initiation toughness, $\mathrm{K}_{\mathrm{fc}}$, predictive models, and automated-ball indentation (ABD) testing are compared. The materials investigated are representative reactor pressure vessel (RPV) steels (several welds and a plate) that were irradiated for other tasks of the Heavy-Section Steel Irradiation (HSSI) Program and are relatively well characterized in the unirradiated and irradiated conditions. They have been annealed at two temperatures, 343 and $454^{\circ} \mathrm{C}$ $\left(650\right.$ and $\left.850^{\circ} \mathrm{F}\right)$ for varying lengths of time. The correlation of the Charpy response and the fracture toughness, $\mathrm{ABI}$, and the response predicted by the annealing model of Eason et al. for these conditions and materials appears to be reasonable. The USE after annealing at the temperature of $454^{\circ} \mathrm{C}$ appears to recover at a faster rate than the TT, and even "over-recovers" (i.e., the recovered USE exceeds that of the unirradiated material).
\end{abstract}

KEYWORDS: annealing, fracture toughness, transition temperature, upper-shelf energy, reactor pressure vessel steels

\section{INTRODUCTION}

One of the options to restore the toughness ${ }^{2}$ properties of RPVs that have been degraded by neutron irradiation is to thermally anneal the vessel. The toughness of

${ }^{1}$ Metals and Ceramics Division, Oak Ridge National Laboratory, P.O. Box 2008, Oak Ridge, TN, 37831-6151, managed by Lockheed Martin Energy Research Corp. under contract DE-AC05-96OR22464 for the U.S. Department of Energy.

${ }^{2}$ In this paper, fracture toughness denotes the properties measured by fracture mechanics tests, e.g., $\mathrm{K}_{\mathrm{Jc}}$, and not the Charpy toughness. 
in-service RPVs is generally monitored via USE and the shift in the 41-J transition temperature $\left(\Delta \mathrm{TT}_{41 \mathrm{~J}}\right)$, determined by Charpy impact tests on surveillance specimens. The research conducted by the HSSI Program at Oak Ridge National Laboratory (ORNL), sponsored by the U.S. Nuclear Regulatory Commission (NRC), is investigating the fracture toughness response to annealing and, in particular, to subsequent reirradiation, as well as correlating toughness to properties determined by Charpy testing. Various factors are known to affect the irradiated, annealed, and reirradiated (IAR) toughness behavior of RPV steels, among which are the postweld heat treatment, copper content, and materials with low initial USE. Another phenomenon to be investigated and described in this paper is the "over-recovery" observed during annealing at $454^{\circ} \mathrm{C}$ for various time durations, in which the USE of irradiated and annealed welds exceeded the values in the unirradiated condition. To investigate the effect of all these variables on toughness would require a very large matrix which would be prohibitively expensive. Consequently, it is necessary to determine whether relatively simpler tests such as Charpy, ABI, and models, such as those of Eason et al., can be used successfully as surrogates for fracture toughness testing. This paper summarizes the correlations obtained to date.

\section{DESCRIPTION OF MATERIAL USED}

The commercially fabricated submerged arc-welds and plate used in this study are commonly used in RPVs. These materials have been extensively characterized in their unirradiated and irradiated conditions [1] [2] [ $[3][\underline{4}]$. Large variations in the copper content (from 0.14 to $0.49 \%$ ) have been observed in welds fabricated using weld wire with copper coating [드. To avoid these large variations, HSSI weld $73 \mathrm{~W}$ was commercially fabricated with copper added to the weld wire melt, consequently this weld has a very small standard deviation in copper content of $0.010 \%$. The "undersized" 73W Charpy V-notch (CVN) specimens used in part of this study were slightly smaller in one cross-sectional dimension than standard full-size CVN specimens. The width of the "undersize" CVN specimens is $95 \%$ of full-size specimens, and for comparison to full-size specimens, the results have been normalized as described below. The difference in the unirradiated CVN 41-J (30-ft-lb) transition temperatures $\left(\mathrm{TT}_{41-\mathrm{J}}\right)$ between the full size and subsize specimens is insignificant, but the USE of the subsize specimen is $87 \%$ that of the full-size specimen. To partially account for such differences in material condition or geometry, the response of all materials have been normalized with respect to the change due to irradiation, as will be discussed below. Such normalization also helps in comparing materials with different exposure, e.g., the subsize $73 \mathrm{~W}$ CVN specimens were irradiated to average exposures of $1.8 \times 10^{19} \mathrm{n} / \mathrm{cm}^{2}(>1 \mathrm{MeV})$, while the full-size specimens were irradiated to $1.5 \times 10^{19} \mathrm{n} / \mathrm{cm}^{2}(>1 \mathrm{MeV})$. For the range of fluences and fluxes of this study, the impact of fluence on the percent recovery of CVN properties is probably of secondary importance compared to the effect of material chemistry, annealing temperature, and time. The nominal irradiation temperature for all materials was $288^{\circ} \mathrm{C}$.

Another commercial weld investigated is the Midland weld, designated WF-70. The copper content varied from 0.21 to $0.46 \%$ with substantial variations in the unirradiated $41-\mathrm{J}$ transition temperature and upper shelf [3] . The average unirradiated 
USE is $90 \mathrm{~J}$, and this weld is classified as a "low USE weld." Material from the nozzle and beltline have been separated because the range in copper content is clearly separable [3] . The other commercial welds investigated, designated HSSI welds $61 \mathrm{~W}$ through $67 \mathrm{~W}$, have chemistry and USE variations similar to those of the Midland weld [ 5 ]. Only one plate material has been investigated to date, Heavy-Section Steel Technology (HSST) Program Plate 02 []].

\section{ANNEALING TEMPERATURES AND TIMES INVESTIGATED}

Irradiated specimens were annealed at two temperatures, 343 and $454^{\circ} \mathrm{C}(650$ and $850^{\circ} \mathrm{F}$ ). These two temperatures have often been investigated as approximate lower and upper bounds of annealing temperatures [7]. The $343^{\circ} \mathrm{C}$ temperature could be used for a wet anneal. This is considerably simpler to perform than a dry anneal at $454^{\circ} \mathrm{C}$ since the reactor internals would not have to be removed. One annealing time of $168 \mathrm{~h}$ was investigated at the $343^{\circ} \mathrm{C}$ temperature and, as described below, the recovery of the TT for some materials was insignificant, but in others the recovery was approximately $50 \%$. In the case of the subsize HSSI weld 73W, four annealing times varying from 1 day to 2 weeks $(336 \mathrm{~h})$ were investigated at a temperature of $454^{\circ} \mathrm{C}$. The rest of the materials were annealed at the two temperatures mentioned for $168 \mathrm{~h}$.

The subsequent reembrittlement rate is as important as the degree of recovery. The reembrittlement rate depends on, among other factors, material, irradiation and annealing temperatures. For VVER-440 steels, after a relatively low temperature anneal at $343^{\circ} \mathrm{C}$, the reembrittlement rate compared to the initial rate was significantly retarded [8]. For other materials annealed at $343^{\circ} \mathrm{C}$ for $168 \mathrm{~h}$, relatively rapid reembrittlement was observed [9]. Moreover, the relative ease of a wet anneal compared to a dry anneal, makes the use of the low annealing temperature attractive. A Belgian reactor, $\mathrm{BR} 3$, was annealed in 1984 at $343^{\circ} \mathrm{C}$ for $168 \mathrm{~h}$ and subsequently operated until 1987 [10]. In the American Society for Testing and Materials (ASTM) Standard Guide for In-Service Annealing of Light-Water Cooled Nuclear Reactor Vessels (E 509-86), there are two methodologies that bracket possible reembrittlement rates: the vertical shift and the lateral shift. For the VVER-440 steels mentioned above, the reembrittlement rate is closer to the vertical shift model. In a recent study by Hawthorne, the reembrittlement rate after annealing at $454^{\circ} \mathrm{C}$ for $168 \mathrm{~h}$ as measured by the "Charpy transition temperature increases were 22 to $43 \%$ of the increase produced by the first cycle irradiation exposure" [11]. Very recent data [12] for HSSI weld 73W suggests that the reembrittlement rate is bracketed between the lateral and vertical shifts. Due to the relative ease of wet anneals, it is suggested that the reembrittlement rates be studied for annealing temperatures of $343^{\circ} \mathrm{C}$.

\section{RESULTS}

The recovery of CVN impact properties is measured by the change in values of the Charpy USE and the 41-J transition temperature, TT, as a result of annealing and are defined below. The values of the USE and TT were calculated from a nonlinear 
regression fit of a hyperbolic tangent equation to the Charpy impact energy data. The hyperbolic tangent equation is of the form:

$$
\mathrm{E}=\frac{\mathrm{USE}+\mathrm{LSE}}{2}+\frac{\mathrm{USE}-\mathrm{LSE}}{2} \operatorname{Tanh}\left(\frac{\mathrm{T}-\mathrm{MTT}}{\mathrm{TZW} / 2}\right),
$$

where

$$
\begin{aligned}
\mathrm{E} & =\text { impact energy } \\
\text { USE and LSE } & =\text { upper- and lower-shelf energy values, respectively, } \\
\mathrm{T} & =\text { test temperature, } \\
\text { MTT } & =\text { mid-transition temperature, and } \\
\text { TZW } & =\text { transition zone width. }
\end{aligned}
$$

The LSE was prescribed to be $2.7 \mathrm{~J}$, the average value obtained by testing five submerged-arc welds at liquid nitrogen temperature of $-196^{\circ} \mathrm{C}$ [3]. The USE, MTT, and TZW are fitting parameters.

The percent recovery of the Charpy properties are referenced to the shift in TT and the drop in USE due to neutron irradiation. A $100 \%$ recovery would indicate that the values of TT and USE after annealing have fully recovered their unirradiated values. The percent recovery of the $\mathrm{TT}_{\text {unirr }}$ is defined as the ratio of the residual transition temperature shift after annealing to the shift due to irradiation:

$$
\% \text { Recovery } \mathrm{TT}_{\mathrm{i} \mathrm{a}}=\frac{\mathrm{TT}_{\mathrm{i}}-\mathrm{TT}_{\mathrm{a}}}{\mathrm{TT}_{\mathrm{i}}-\mathrm{TT}_{\text {unir }}} \cdot 100,
$$

where TT is the transition temperature at the 41-J energy level for the condition indicated by the outer subscript. The percent recovery of the USE is defined in an analogous manner:

$$
\% \text { Recovery } \mathrm{USE}_{\mathrm{ia}}=\frac{\mathrm{USE}_{\mathrm{a}}-\mathrm{USE}_{\mathrm{i}}}{\mathrm{USE}_{\text {unir }}-\mathrm{USE}_{\mathrm{i}}} \cdot 100 .
$$

A representative response of Charpy energy to annealing at $454^{\circ} \mathrm{C}$ for $168 \mathrm{~h}$ of HSSI weld $73 \mathrm{~W}$ Charpy specimens in the unirradiated, irradiated, and irradiated/annealed conditions is shown in Fig. 1. The three curves shown are the least-squares mean fits of Eq. (1) to the experimental results. Also shown are the percent recoveries in USE and TT computed from Eqs. (2) and (3). The values used in either Eqs. (2) or (3) are those calculated from the mean curves. Details of the results of testing the undersize HSSI weld $73 \mathrm{~W}$ may be found elsewhere [13]. The response of Charpy energy to annealing at $343^{\circ} \mathrm{C}$ for $168 \mathrm{~h}$ of this same material is shown in Fig. 2, from which it may be seen that the USE has recovered about $50 \%$ of the drop lost to irradiation, but the recovery of the $\mathrm{TT}_{41-\mathrm{J}}$ is 


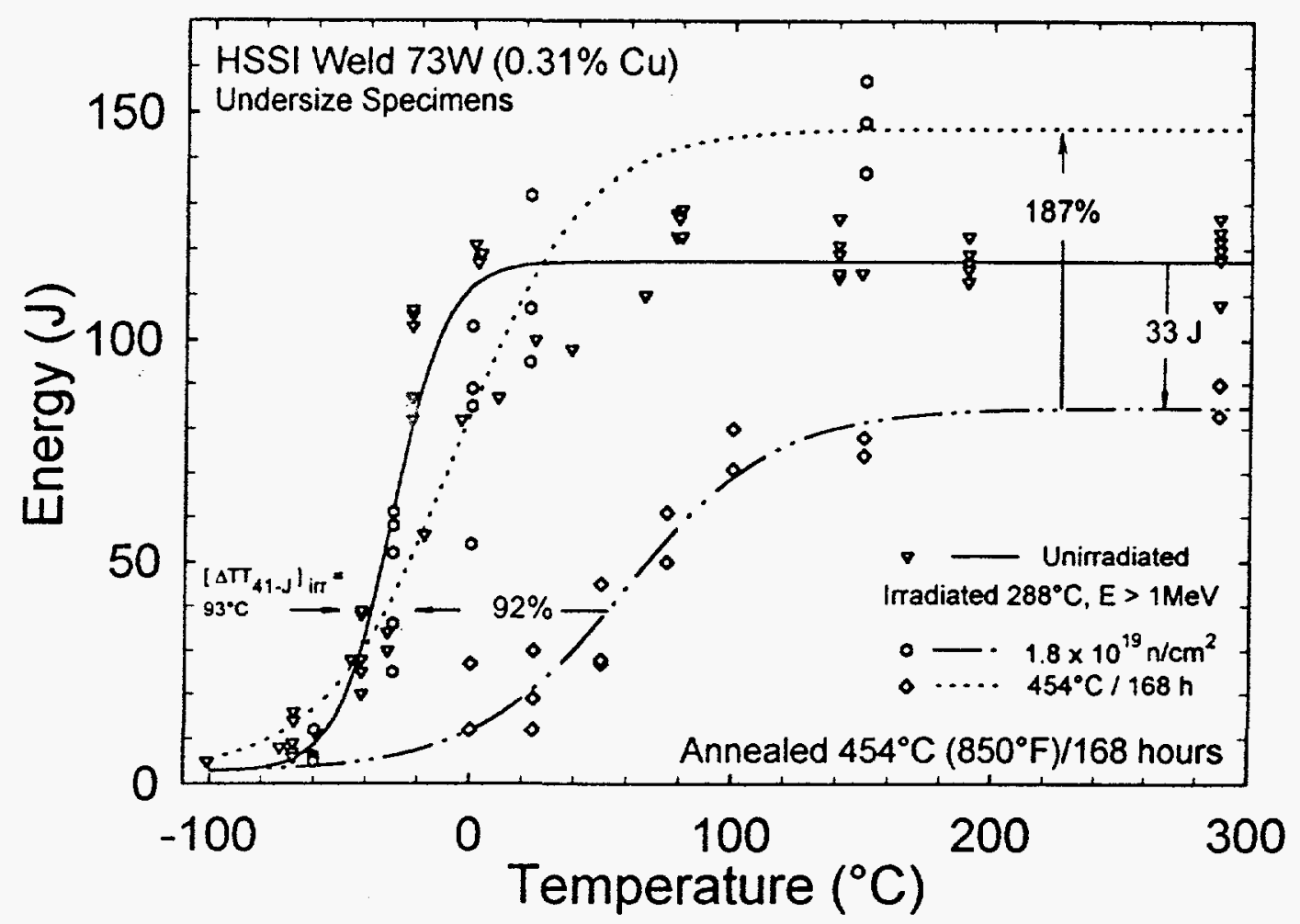

FIG. 1--Charpy energy response to annealing at $454^{\circ} \mathrm{C}$ for $168 \mathrm{~h}$ for HSSI weld $73 \mathrm{~W}$.

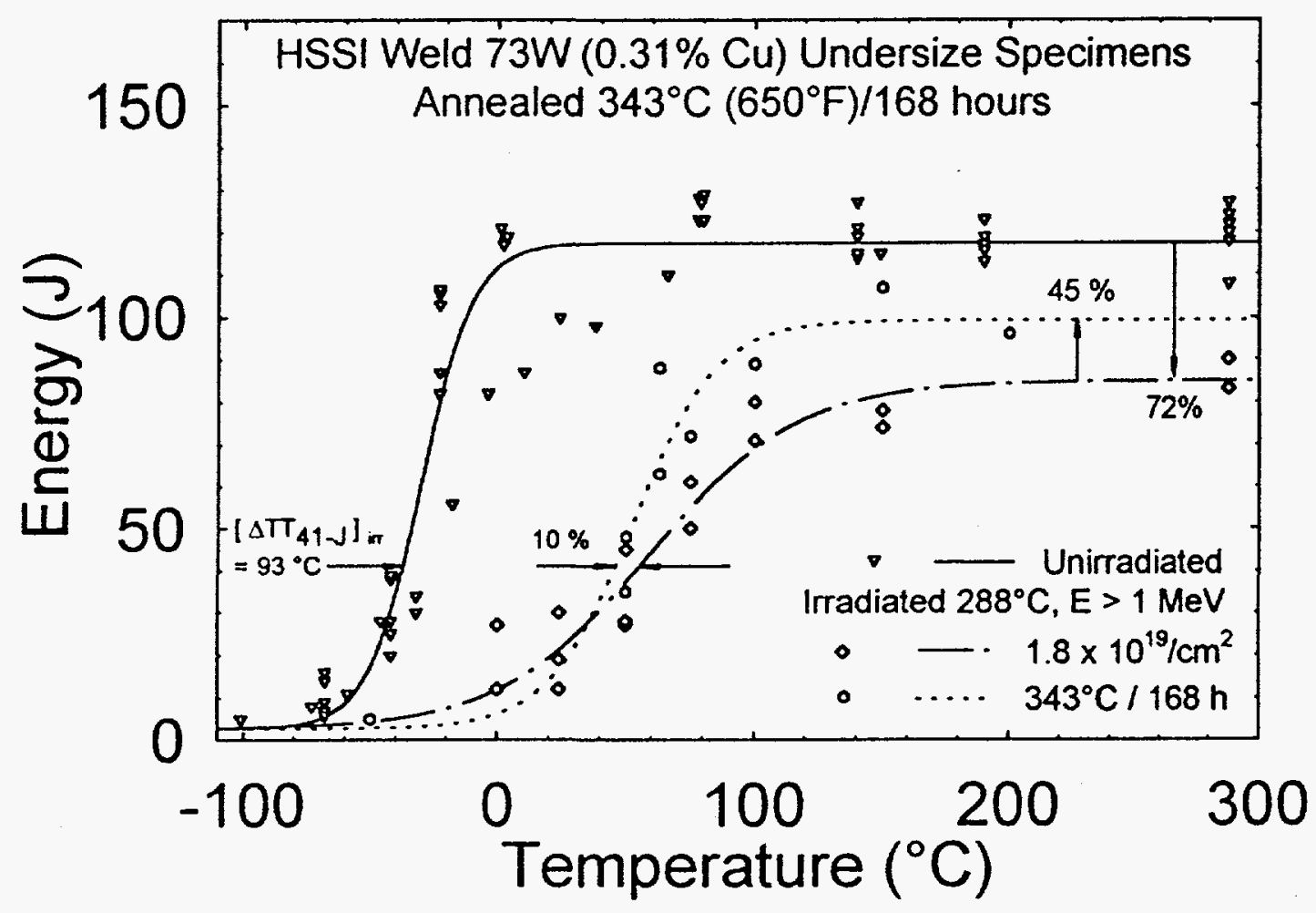

FIG. 2--Charpy energy response to annealing at $343^{\circ} \mathrm{C}$ for $168 \mathrm{~h}$ for HSSI weld $73 \mathrm{~W}$. 
insignificant. For the materials investigated, the recovery of the $\mathrm{TT}_{41 . \mathrm{J}}$ due to annealing at $343^{\circ} \mathrm{C}$ ranged from insignificant to about $50 \%$ of the shift due to irradiation (see Fig. 3).

One of the results of this investigation is that annealing "over-recovered" the USE, meaning that USE recovered to values greater than those of unirradiated specimens. It is of interest to note that similar behavior was observed for the initiation toughness $\left(\mathrm{J}_{\mathrm{Ic}}\right)$ of irradiated welds [14]. Annealing, tempering, and aging effects are diffusion processes where temperature is the dominant parameter and time at temperature is of secondary influence. As part of the original fabrication procedure, HSSI weld $73 \mathrm{~W}$ was postweld heat treated at $607^{\circ} \mathrm{C}\left(1125^{\circ} \mathrm{F}\right)$ for $40 \mathrm{~h}$, and thus exposure at the lower temperature of $454^{\circ} \mathrm{C}$ for $168 \mathrm{~h}$ would not be expected to have any effect. To determine whether this increase in USE was due to irradiation, unirradiated specimens were also aged at 460 and $490^{\circ} \mathrm{C}$, and an analogous over-recovery was also observed. Thus, over-recovery is not an effect of irradiation only. The reasons for this phenomenon are still under investigation. To compare the recovery of aged but unirradiated specimens to the before-aged condition, the following definition could be used:

$$
\% \text { Recovery USE' }=\frac{U^{U S E}}{U^{\prime} E_{\text {unirr }}} \cdot 100,
$$

where USE' is the USE for the condition studied. By using Eq. (4), both unirradiated and irradiated HSSI weld $73 \mathrm{~W}$ appear to have overrecovered to about the same degree.

It should be noted that the USE recovers at a much faster rate than the TT. In Fig. 4, the recovery of both these Charpy properties is compared for HSSI weld $73 \mathrm{~W}$ for various annealing times, and it appears both USE and TT recover initially at a relatively fast rate. The TT then recovers at a relatively slow rate after annealing times of about $100 \mathrm{~h}$, with diminishing returns, even for doubling the annealing time. In contrast, the USE continues to recover at a significant rate, although at a much slower rate than the initial recovery rate. The difference in recovery rates of the TT and USE for HSSI weld $73 \mathrm{~W}$ is shown in Fig. 5. The faster recovery, and even over-recovery, of the USE compared to that of the TT is significant when the annealing of RPVs is considered. Although the mechanisms involved in each case are different, the implication is that if the TT recovers, then there is a high probability that the USE has recovered at least as much, or even more.

Wet annealing of an RPV at $343^{\circ} \mathrm{C}$ should not be discounted as ineffective before the annealing response of the critical material is investigated. The recovery of HSSI weld $73 \mathrm{~W}$ was insignificant; however, the recoveries of the Midland weld and HSST Plate 02 due to thermal annealing at $343^{\circ} \mathrm{C}$ for $168 \mathrm{~h}$ were approximately 50 and $36 \%$, respectively. Thus, for such materials, a $343^{\circ} \mathrm{C}$ wet thermal annealing temperature could be considered. Even for the $343^{\circ} \mathrm{C}$ anneals, the materials that exhibited a substantial recovery in TT also recovered nearly $100 \%$ of the drop in USE that was lost due to irradiation. This appears to have been the experience of other investigators, as depicted in 


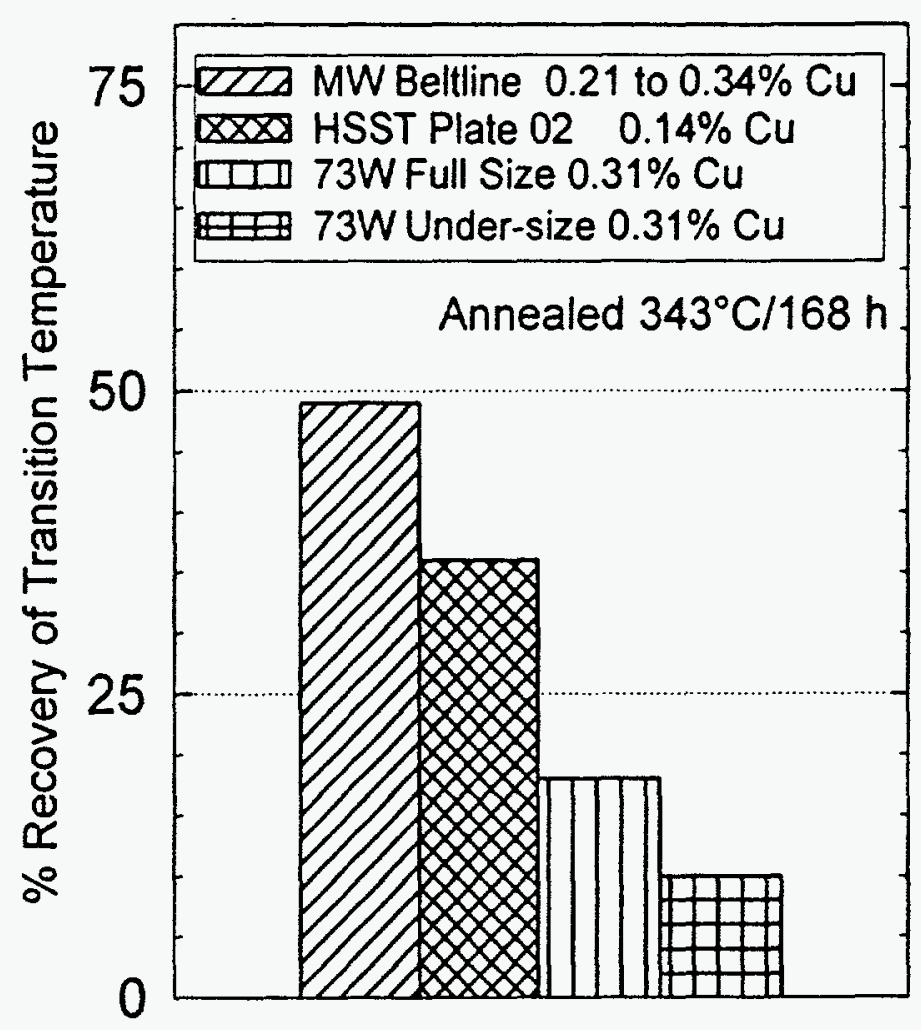

FIG. 3--Comparison of the recovery of various welds and a base metal plate due to annealing at $343^{\circ} \mathrm{C}$ for $168 \mathrm{~h}$.

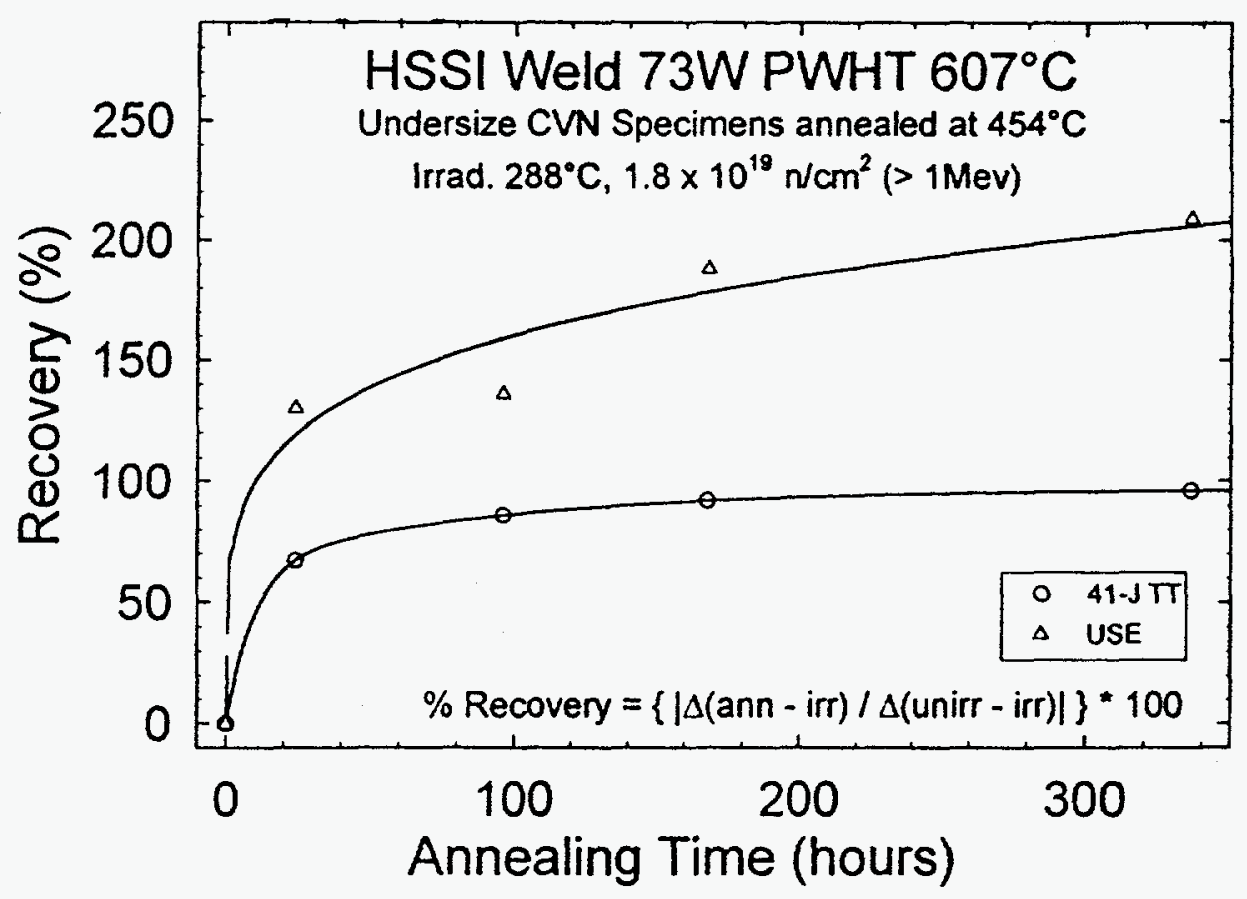

FIG. 4--Comparison of the rates of recovery of TT and USE as a function of annealing time for HSSI weld $73 \mathrm{~W}$. 


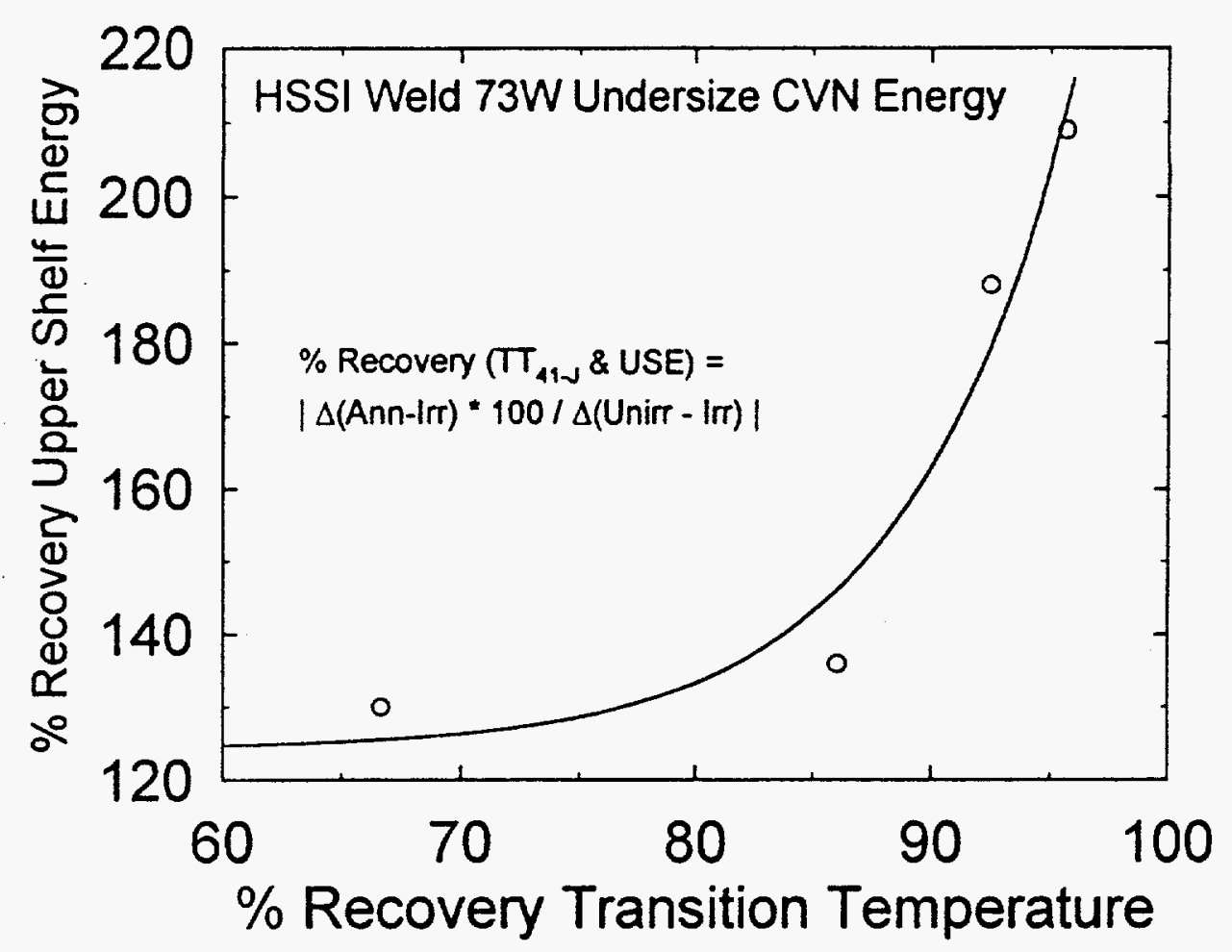

FIG. 5--Comparison of the recovery rate of USE to that of TT for HSSI weld 73W.

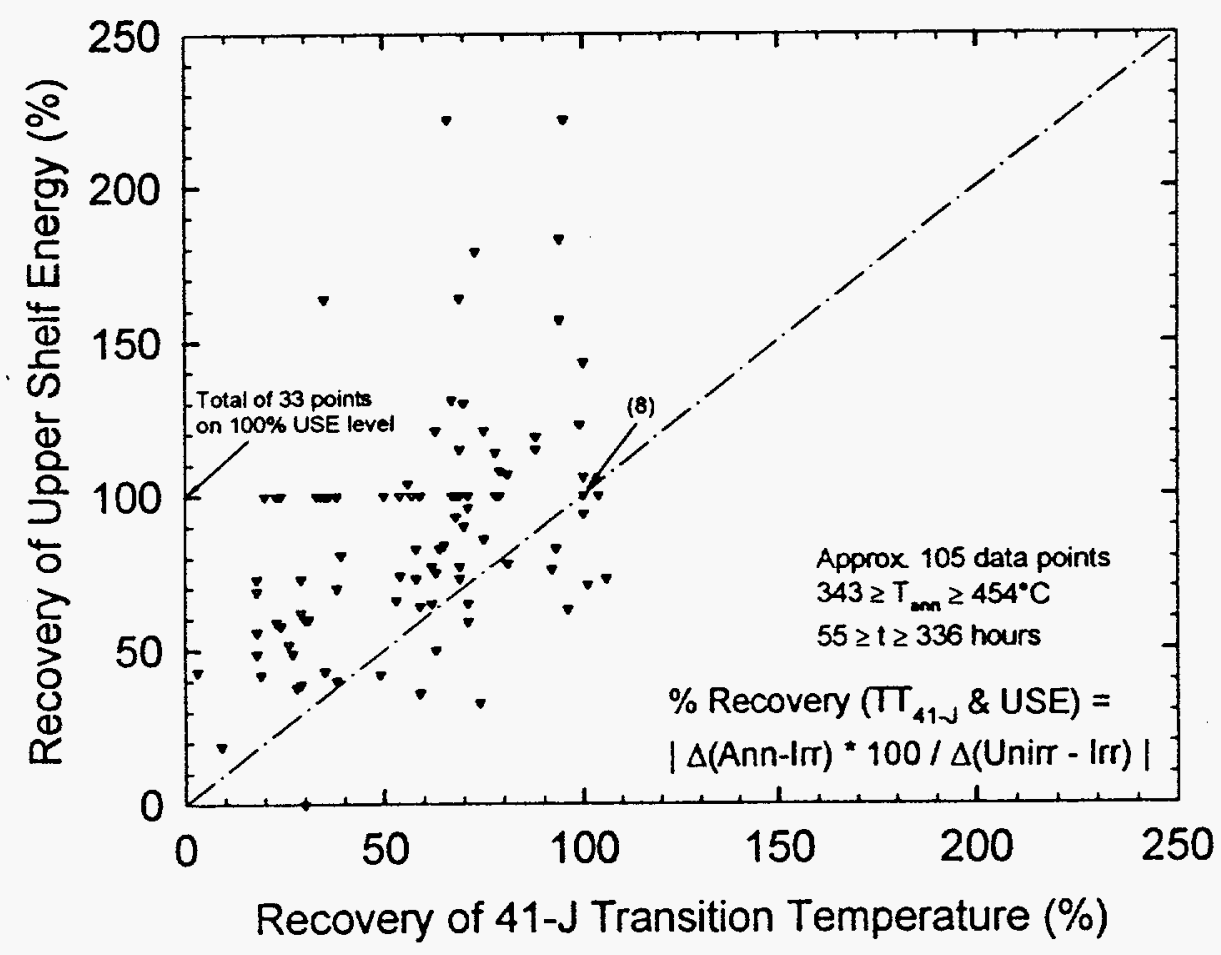

FIG. 6--Comparison of the recovery of TT and USE for various materials, annealing times, and temperatures. 

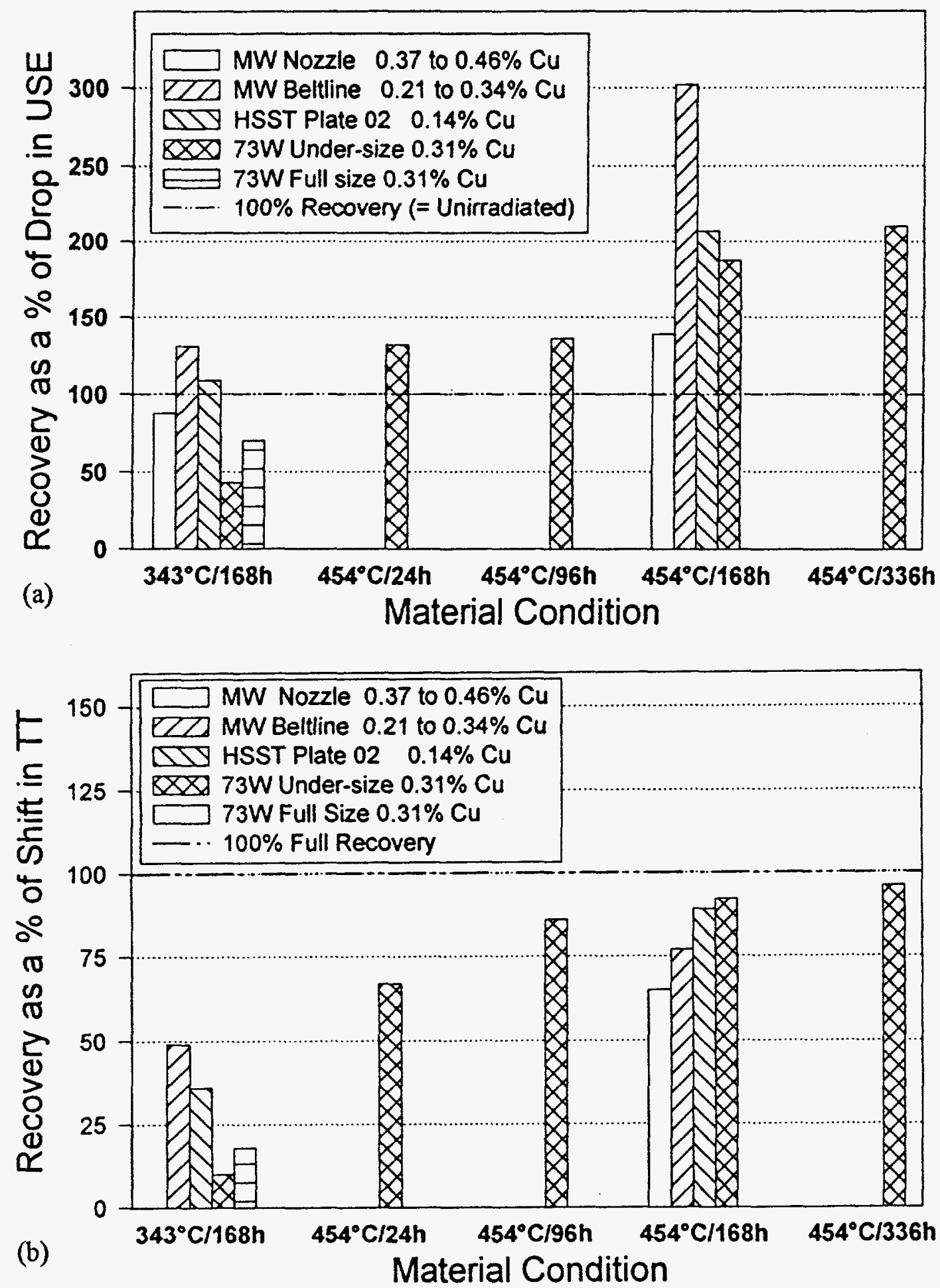
studied.

FIG. 7--Comparison of the recovery of (a) USE and (b) TT for the welds and plate 
Fig. 6, which has been compiled by ORNL from test reactor data [15]. This has been further confirmed by results at ORNL [see Fig. 7(a)]. In the latter figure, many of the materials recovered and, in some cases, overrecovered most of the USE lost due to irradiation, but the shift in TT was never fully recovered after annealing at $343^{\circ} \mathrm{C}$ [Fig. 7(b)].

It should be noted that overrecoveries of $300 \%$ of the USE such as those exhibited by the Midland beltline weld [Fig. 7(a)] could be misleading unless the values of the changes are closely examined. In the case of the Midland beltline weld, the recovery of and drop in USE [the numerator and denominator of Eq. (3)], are about 26 and $9 \mathrm{~J}$, respectively, and a large portion of these changes could be due to scatter. The recovery as defined by Eq. (4) is $119 \%$ in this case, which takes into account the change in USE relative to the value of the USE in the unirradiated condition. The relative merits and disadvantages of each of Eqs. (3) and (4) have been discussed previously [13].

The comparisons of the predicted USE and TT due to thermal annealing to those determined experimentally are shown in Fig. 8(a) and (b), respectively. The predictive model used has been developed by Eason et al. [16] using available experimental data. It should be noted that the experimental data shown in Fig. 8 were not available at the time the model was developed, and thus do not form part of the database upon which the model was based. In both Fig. 8(a) and (b), experimental data that fall on the solid line would indicate that the model gives a perfect prediction. The other two dash-dot-dot lines in each figure are twice the margins of standard errors in the model, ${ }^{3} 2 \mathrm{~S}_{\mathrm{e}}$, as given by Eason et al. Due to the uncertainty in the copper content of the material, a range of predicted values corresponding to the range in copper content is shown as a vertical bar through the data points for the Midland weld with "caps" on each end. Thus, the models predict both USE and TT within $2 \mathrm{~S}_{e}$, or are conservative in prediction, namely, underpredict the USE or overpredict the TT.

In the case of toughness testing in the transition temperature range, the following relationship between the median fracture toughness for $1 \mathrm{~T} \mathrm{C}(\mathrm{T})$ specimens in the transition region, $\mathrm{K}_{\mathrm{J}(\mathrm{med})}$, and temperature is used:

$$
\mathrm{K}_{\mathrm{J}(\text { med })}=30+70 \exp \left[0.019\left(\mathrm{~T}-\mathrm{T}_{0}\right)\right] \text {, }
$$

${ }^{3}$ The standard error (an abbreviation of "standard error of the mean") is a statistic that quantifies the certainty with which the mean computed from a random sample estimates the true mean of the population from which the sample was drawn. This is different from the "sample standard deviation." 

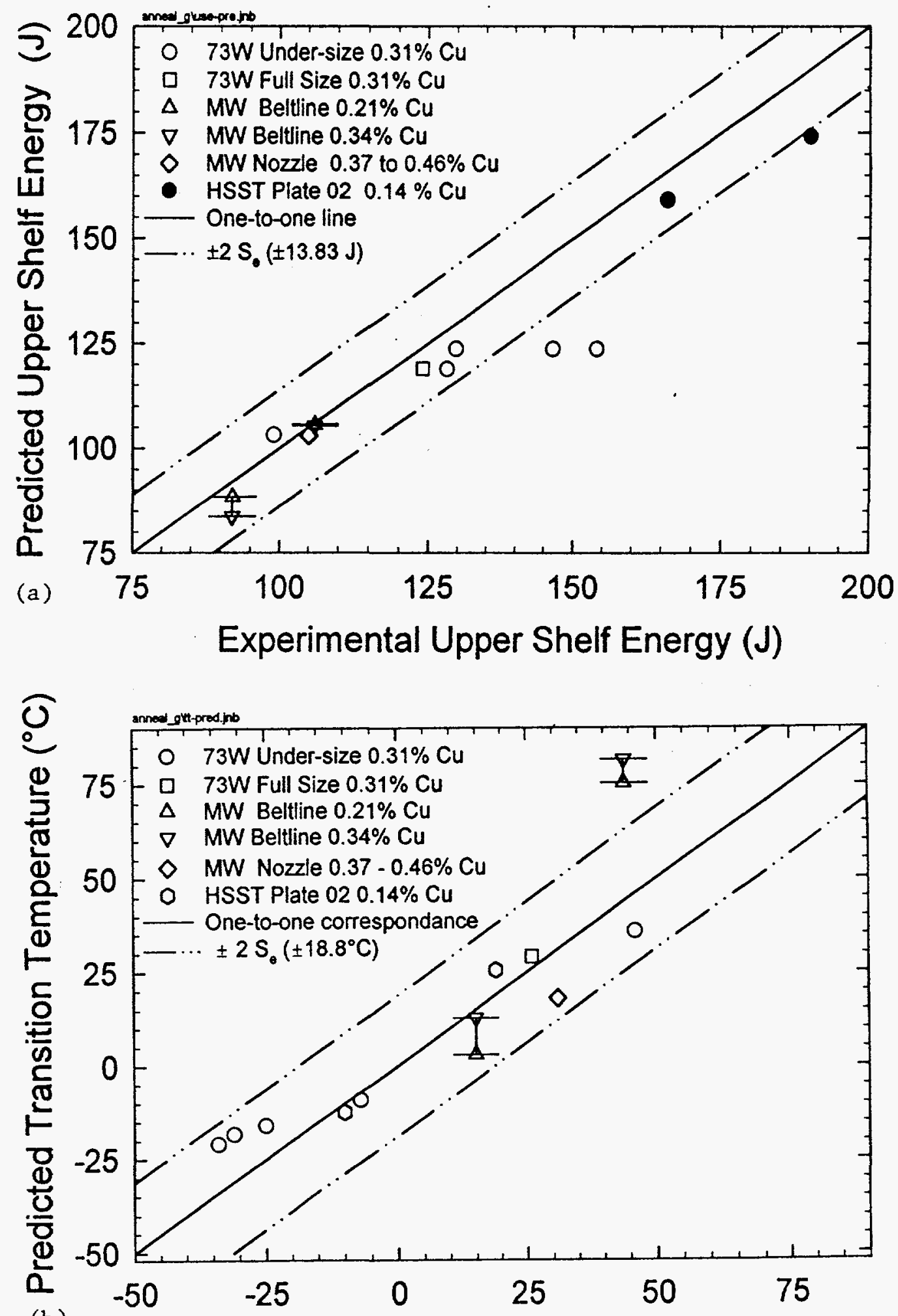

(b) Experimental Transition Temperature $\left({ }^{\circ} \mathrm{C}\right)$

FIG. 8--Comparison of the predicted (a) USE and (b) TT to the experimentally determined values of irradiated reactor pressure vessel steels when thermally annealed. 
where $T_{0}$ is a reference temperature which, together with $\mathrm{K}_{\mathrm{Ic}(\mathrm{med})}$, is obtained using procedures that are in the process of being developed into an ASTM standard. ${ }^{4}$ The differences between the respective $T_{0}$ values are used as measures of the effect of annealing. A typical result is shown in Fig. $9(\mathrm{a})$, which shows three sets of $\mathrm{K}_{\mathrm{Jc(med)}}$ curves for each of the unirradiated, irradiated and annealed conditions. Detailed results have been published [17]. In Fig. 9(b), the corresponding Charpy results are shown, and it may be seen that the recovery of either toughness or Charpy energy, are within errors of scatter, comparable. Figure 10 compares for base metal HSST Plate 02 material the TT shift of either Charpy energy or $T_{0}$ in irradiated and annealed conditions. The recovery due to thermal annealing at $454^{\circ} \mathrm{C}$ is large, but that at $343^{\circ} \mathrm{C}$ is somewhat inconsistent; in one case, the recovery of the Charpy energy is significant, but in another, the recovery of toughness is not.

The ABI technique [18] was also used to determine the extent of recovery. Figure 11 shows the true stress versus true plastic strain derived from the ABI test on HSST Plate 02 in the unirradiated, irradiated, and two annealed conditions at 343 and $454^{\circ} \mathrm{C}$. The recovery due to annealing at $454^{\circ} \mathrm{C}$ appears to be complete; the true stress versus true plastic strain curve derived from the ABI test on HSST Plate 02 annealed at $454^{\circ} \mathrm{C}$ is indistinguishable from that of the unirradiated material, which compares reasonably well with the TT and USE for the same material (Fig. 7).

As a second example of the use of the $\mathrm{ABI}$ technique, the ABI-deduced yield strength was measured on five irradiated specimens of various low USE welds [ $\underline{\text { ] }}$. These five specimens were then annealed at $454^{\circ} \mathrm{C}$ for $168 \mathrm{~h}$, and the ABI-deduced yield strength was then measured again on the same five specimens. The percent recovery, calculated in the same manner as percent recovery of the Charpy TT, using the changes in ABI-deduced yield strength in place of TT in Eq. (2), ranged from about 60 to $100 \%$. Figure 12 shows the changes in the ABI-deduced yield strength due to irradiation and subsequent annealing, since the absolute values of the changes are useful in evaluating the extent of change in the ABI-deduced yield strength. The values of irradiated and annealed tensile yield strengths for these specimens are unavailable.

\section{SUMMARY}

The correlation among the various measures of the annealing response for the materials and conditions investigated in this paper seems to be reasonable. In particular:

1. The USE recovers at a faster rate than the TT for all the materials investigated.

2. The USE over-recovers for thermal annealing at $454^{\circ} \mathrm{C}$, but TT recovery was never equal to nor better than $100 \%$.

${ }^{4}$ Determination of Reference Temperature, $T_{a}$ for Ferritic Steels in the Transition Range, Draft 13, Task Group E08.08.03 on Ductile-Brittle Transition, American Society for Testing and Materials, Philadelphia, 1996. 


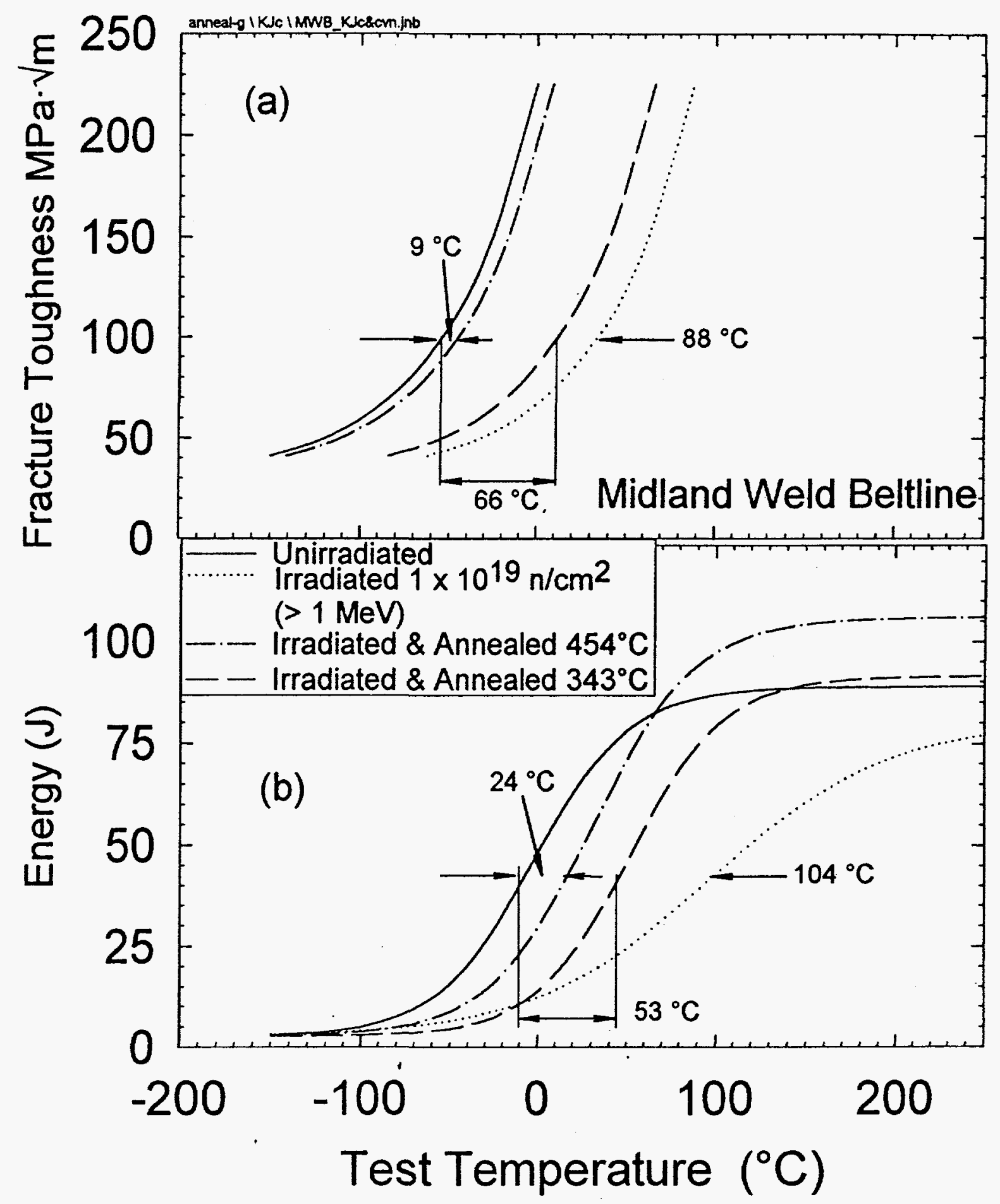

FIG. 9--Comparison of the (a) median fracture toughness and (b) Charpy energy of the Midland beltline weld in the unirradiated, irradiated and irradiated/annealed conditions. The irradiated specimens were annealed at $454^{\circ} \mathrm{C}$ for $168 \mathrm{~h}$. 


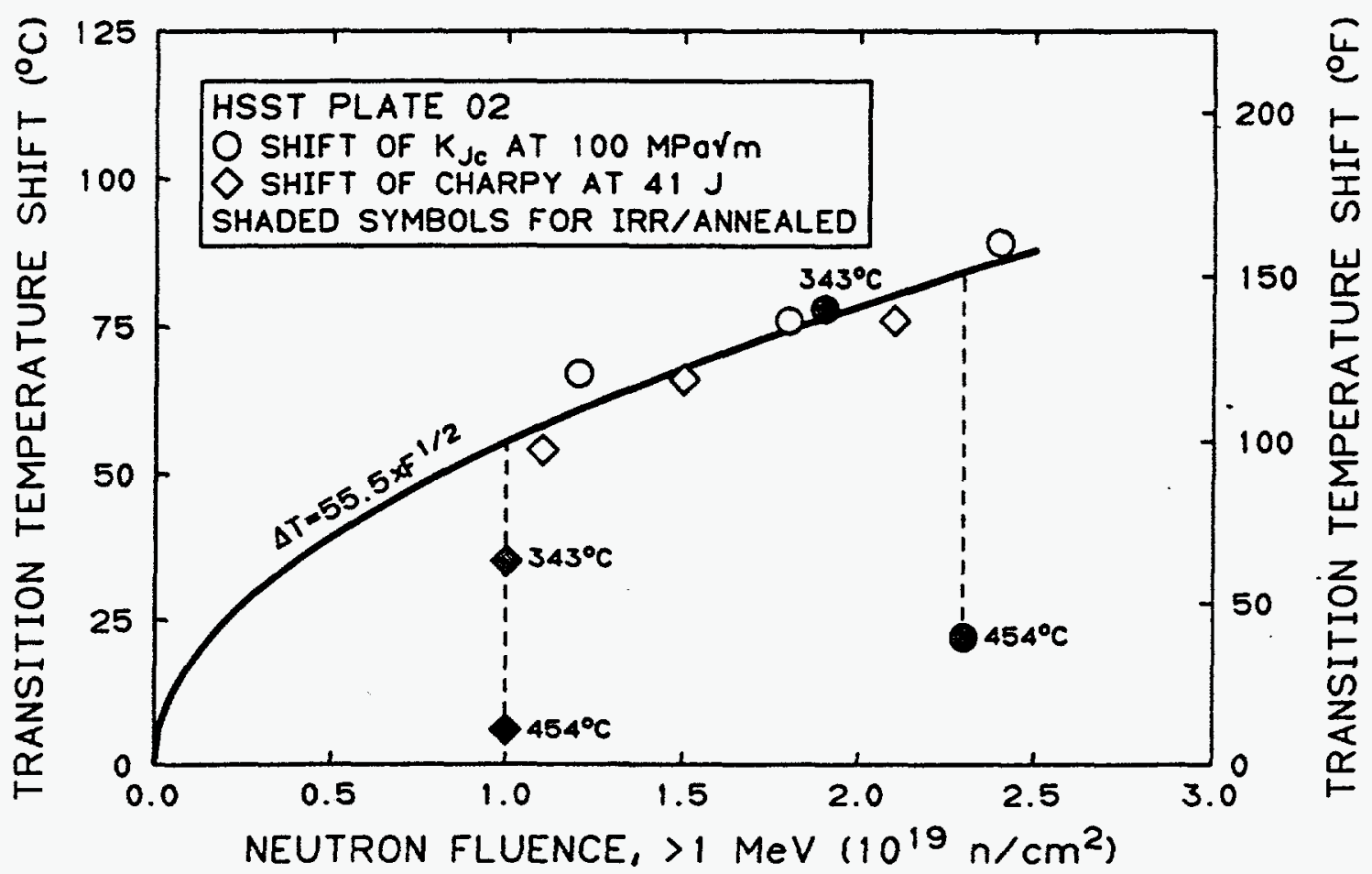

FIG. 10--Comparison of the shifts in median fracture toughness and transition temperatures of HSST Plate 02 in the unirradiated, irradiated and irradiated/annealed conditions.

3. The annealing model of Eason et al. appears to predict, within twice the error, conservatively both the USE and the TT.

4. For the limited number of fracture toughness tests performed to date, the recovery of the fracture toughness and Charpy energy is similar. More testing is planned.

5. The ABI technique also offers a relatively inexpensive method to perform extensive investigations to screen the hardening and yield strength response of various materials to IAR.

Since fracture toughness based on fracture mechanics is the fundamental property that is used in integrity evaluations, Charpy and $\mathrm{ABI}$ testing can only be used as approximate indicators of IAR response, and ultimately the results must be confirmed using fracture toughness testing.

\section{ACKNOWLEDGMENTS}

This research is sponsored by the Office of Nuclear Regulatory Research, U.S. Nuclear Regulatory Commission, under Interagency Agreement DOE 1886-8109-8L with the U.S. Department of Energy under Contract No. DE-AC05-96OR22464 


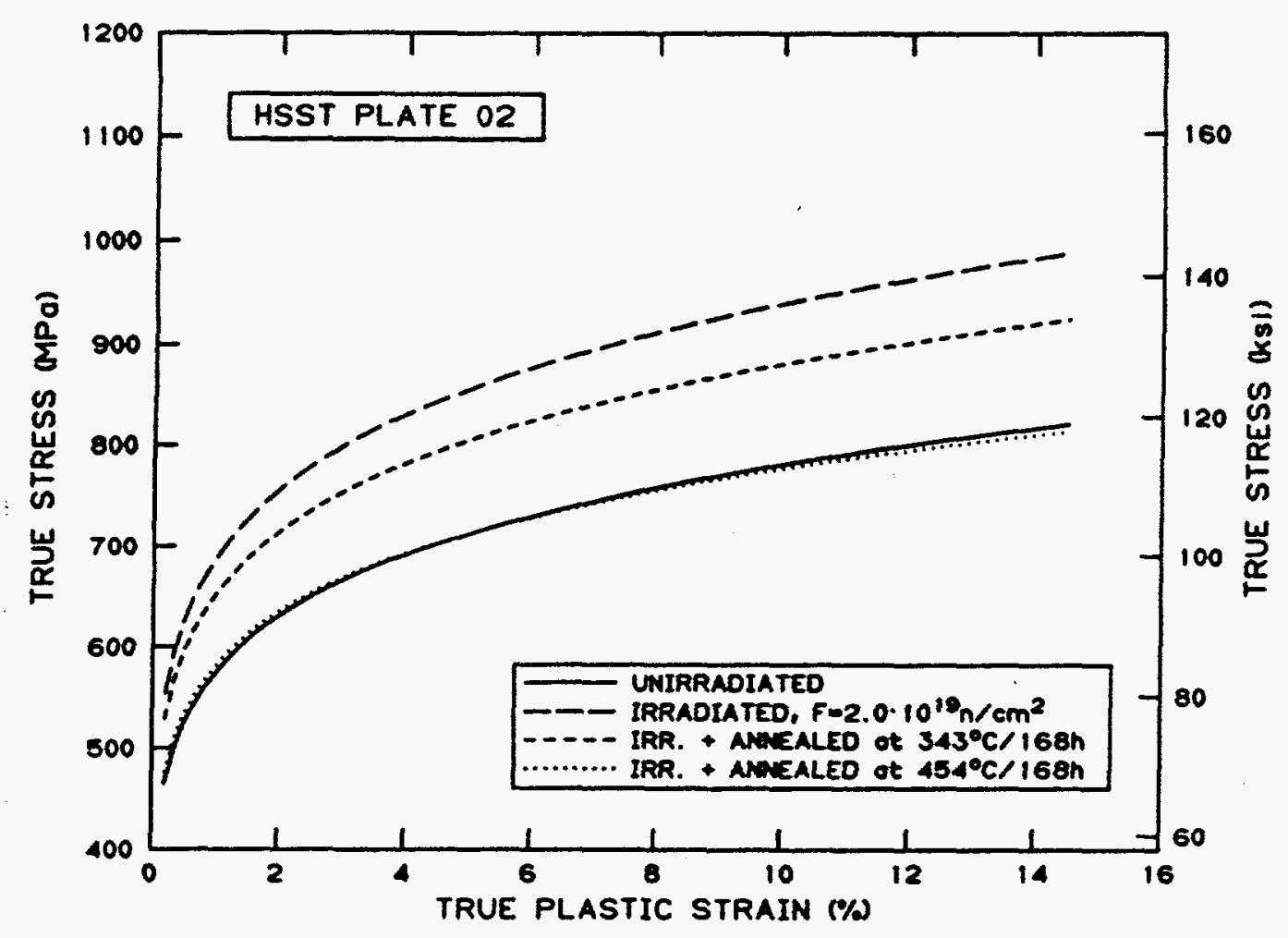

FIG. 11--The ABI-deduced true-stress versus true strain for HSST Plate 02 in the unirradiated, irradiated, irradiated/annealed conditions.

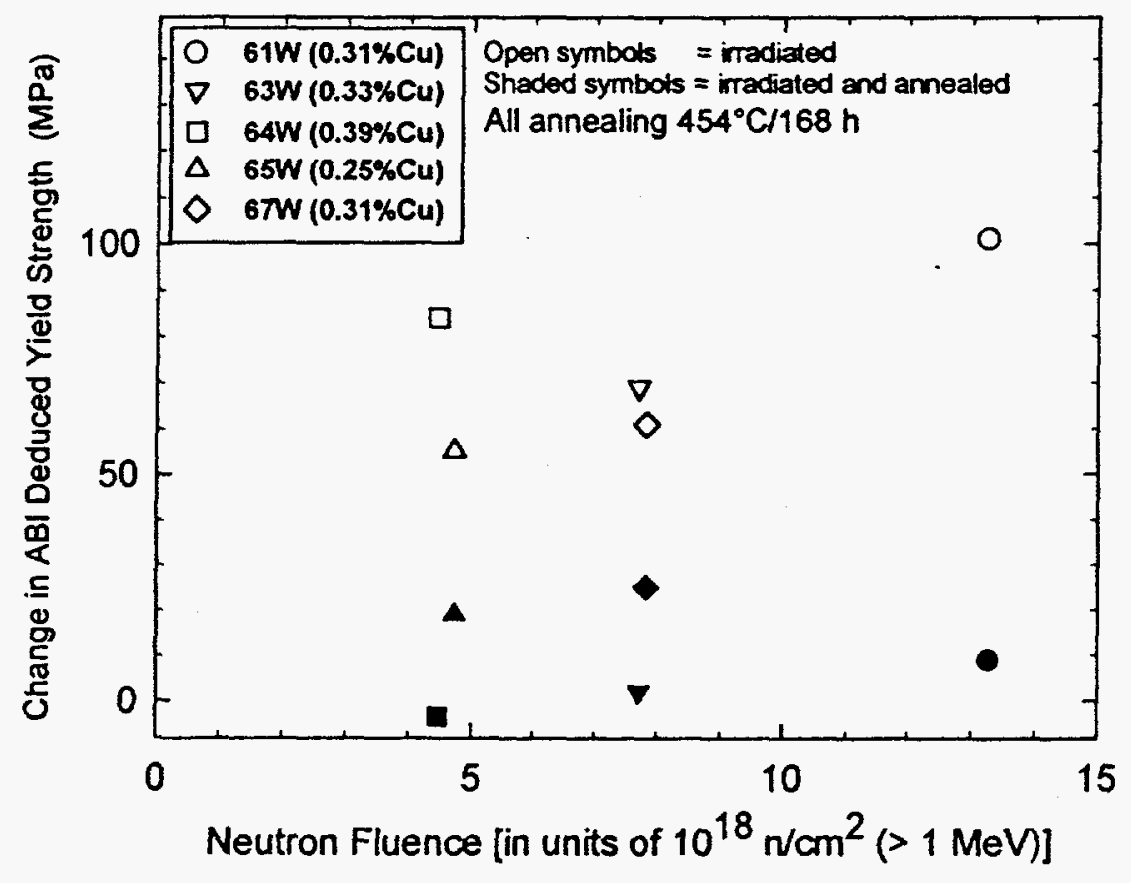

FIG. 12--Comparison of ABI-deduced yield strength of various low USE welds in the irradiated and irradiated/annealed conditions. 
with Lockheed Martin Energy Research Corp. The authors would like to thank Donald E. McCabe and the ASTM reviewers for peer review and Julia L. Bishop for preparation of the manuscript.

\section{REFERENCES}

[1] Nanstad, R. K., McCabe, D. E., Menke, B. H., Iskander, S. K., and Haggag F. M., "Effects of Irradiation on $\mathrm{K}_{\mathrm{Ic}}$ Curves for High-Copper Welds," pp. 214-233 in Effects of Radiation on Materials, 14th International Symposium (Volume II), ASTM STP 1046, N. H. Packan, R. E. Stoller, and A. S. Kumar, Editors, American Society for Testing and Materials, Philadelphia, 1990.

[2] Iskander, S. K., Corwin, W. R., and Nanstad, R. K., "Effects of Irradiation on Crack-Arrest Toughness of Two High-Copper Welds," pp. 251-269 in Effects of Radiation on Materials: 15th International Symposium, ASTM STP 1125, R. E. Stoller, A. S. Kumar, and D. S. Gelles, Eds., American Society for Testing and Materials, Philadelphia, 1992.

[ 3 ] Nanstad, R. K., McCabe, D. E., Swain, R. L., and Miller, M. K., Chemical Composition and $R T_{N D T}$ Determinations for Midland Weld WF-70, NUREG/CR-5914 (ORNL-6740), Oak Ridge National Laboratory, Oak Ridge, Tenn., December 1992.

[4] McCabe, D. E., Nanstad, R. K., Iskander, S. K., and Swain, R. L., Unirradiated Material Properties of Midland Weld WF-70, NUREG/CR-6249

(ORNL/TM-12777), Oak Ridge National Laboratory, Oak Ridge, Tenn., October 1994.

[5] Nanstad, R. K., and Berggren, R. G., Irradiation Effects on Charpy Impact and Tensile Properties of Low Upper-Shelf Welds, HSSI Series 2 and 3, NUREG/CR-5696 (ORNL/TM-11804), Oak Ridge National Laboratory, Oak Ridge, Tenn., August 1991.

[6] Stelzman, W. J., Berggren, R. G., and Jones, Jr., T. N., ORNL Characterization of Heavy-Section Steel Technology Program Plates 01, 02, 03, NUREG/CR-4092 (ORNL/TM-9491), Oak Ridge National Laboratory, Oak Ridge, Tenn., April 1985.

[7] Mager, T. R., and Lott, R. G., Thermal Annealing of an Embrittled Reactor Pressure Vessel, EPRI NP-6113-M, Electric Power Research Institute, Palo Alto, Calif., January 1989. 
[8] Kryukov, A. M. and Sokolov, M. A., "Investigation of Material Behavior Under Reirradiation after Annealing Using Subsize Specimens," pp. 417-423 in Small Specimen Test Techniques Applied to Nuclear Reactor Vessel Thermal Annealing and Plant Life Extension, ASTM STP 1204, W. R. Corwin, F. M. Haggag, and W. L. Server, Eds., American Society for Testing and Materials, Philadelphia, 1993.

[9] Hawthorne, J. R., and Hiser, A. L., Irradiation and Irradiation-AnnealReirradiation Studies of RPV Steels and Welds in Support of the BR-3 Reactor, MEA-2218, Materials Engineering Associates, Inc., Lanham, Maryland, November 1988.

[10] Fabry, A., et al., "Research to Understand the Embrittlement Behavior of Yankee/BR3 Surveillance Plate and Outlier RPV Steels," pp. 138-187 in Effects of Radiation on Materials: 17th International Symposium, ASTM STP 1270, D. S. Gelles, R. K. Nanstad, A. S. Kumar, and E. A. Little, Eds., American Society for Testing and Materials, Philadelphia, 1996.

[11] Hawthorne, J. R., Experimental Tests of Irradiation-Anneal-Reirradiation Effects on Mechanical Properties of RPV Plate and Weld Materials, SAND96-0119, Sandia National Laboratories, Albuquerque, New Mexico, January 1996.

[12] R. K. Nanstad, S. K. Iskander, M. A. Sokolov, A. A. Chernobaeva, Y. A. Nikolaev, A. M. Kryukov, and Y. N. Korolev, "Effects of Thermal Annealing and Reirradiation on Toughness of Reactor Pressure Vessel Steels," pp. 99-110 in Proceedings of the U.S. Nuclear Regulatory Commission, Twenty-Fourth Water Reactor Safety Information Meeting, NUREG/CP-0157, Vol. 2, February 1997.

[13] Iskander, S. K., Sokolov, M. A., and Nanstad, R. K., "Effects of Annealing Time on the Recovery of Charpy V-Notch Properties of Irradiated High-Copper Weld Metal," pp. 277-293 in Effects of Radiation on Materials: 17th Volume, STP 1270, D. S. Gelles, R. K. Nanstad, A. S. Kumar, and E. A. Little, Eds., American Society for Testing and Materials, Philadelphia, 1996.

[14] Sokolov, M. A., Nanstad, R. K., and Iskander, S. K., "The Effect of Thermal Annealing on the Fracture Toughness of Low Upper-Shelf Welds," pp. 690-705 in Effects of Radiation on Materials: 17th Volume, STP 1270, D. S. Gelles, R. K. Nanstad, A. S. Kumar, and E. A. Little, Eds., American Society for Testing and Materials, Philadelphia, 1996.

[15] Stallmann, F. W., Wang, J. A., and Kam, F. B. K., TR-EDB: Test Reactor Embrittlement Data Base, Version 1, NUREG/CR-6076 (ORNL/TM-12415), Oak Ridge National Laboratory, Oak Ridge, Tenn., January 1994. 
[16] Eason, E. D., Wright, J. E., Nelson, E. E., Odette, G. R., and Mader, E. V., Models for Embrittlement Recovery Due to Annealing of Reactor Pressure Vessel Steels, NUREG/CR-6327 (MCS 950302), Modeling and Computing Services, Boulder, Colo., May 1995.

[17] Sokolov, M. A., McCabe, D. E., Nanstad, R. K and Iskander, S. K., "Comparison of Fracture Toughness and Charpy Impact Properties Recovery by Thermal Annealing of Irradiated Reactor Pressure Vessel Steels," pp. 771-782 in Proceedings of the Seventh International Symposium on Environmental Degradation of Materials in Nuclear Power Systems - Water Reactors, G. Airey et al., Eds., Breckenridge, Colorado, August 1995.

[18] Haggag, F. M., "In-Situ Measurements of Mechanical Properties Using Novel Automated Ball Indentation System," pp. 27-44 in Small Specimen Test Techniques Applied to Nuclear Reactor Vessel Thermal Annealing and Plant Life Extension, ASTM STP 1024, W. R. Corwin, F. M. Haggag, and W. L. Server, Eds., American Society for Testing and Materials, Philadelphia, 1993. 